\title{
Crossed polysyndactyly
}

INSERM

\section{Source}

INSERM. (1999). Orphanet: an online rare disease and orphan drug data base. Crossed polysyndactyly. ORPHA:2935

Crossed polysyndactyly is a rare, genetic, congenital limb malformation disorder characterized by unilateral or bilateral postaxial polydactyly in the hands and preaxial polydactyly in the feet, associated with bilateral cutaneous syndactyly of first, second and third toes. Cutaneous syndactyly in hands has also been reported in some patients. There have been no further descriptions in the literature since 1994. 